\title{
Leukoaraiosis, intracerebral hemorrhage, and functional outcome after acute stroke thrombolysis OPEN
}

Kannikar Kongbunkiat, MD

Duncan Wilson, MD

Narongrit Kasemsap, MD

Somsak Tiamkao, MD

Fatima Jichi, MSc

Vanessa Palumbo, MD

Michael D. Hill, MD,

FRCPC

Alastair M. Buchan, MD, FRCP

Simon Jung, MD

Heinrich P. Mattle, MD

Nils Henninger, MD

David J. Werring, FRCP, $\mathrm{PhD}$

Correspondence to

Dr. Werring:

d.werring@ucl.ac.uk

Editorial, page 612

Supplemental data at Neurology.org

\section{ABSTRACT}

Objective: To perform a systematic review and pooled meta-analysis of published studies to assess whether the presence of leukoaraiosis on neuroimaging before treatment with thrombolysis (IV or intra-arterial) is associated with an increased risk of symptomatic intracerebral hemorrhage (sICH) or poor functional outcome.

Methods: We included studies of patients with acute ischemic stroke, treated with IV or intraarterial thrombolysis, which assessed functional outcome (3-month modified Rankin Scale [mRS]) or sICH in relation to leukoaraiosis on pretreatment neuroimaging (CT or MRI). We used random-effects models to calculate pooled relative risks (RR) of sICH and poor functional outcome ( $m R S \geq 2)$ for any vs no leukoaraiosis (using any rating scale) and for no to mild vs moderate to severe leukoaraiosis (using the Van Swieten or Fazekas Schmidt scale).

Results: We identified 15 studies (total $n=6,967)$. For sICH outcome, the RR was 1.65 ( $n=5,551$; $95 \%$ confidence interval [CI] 1.26-2.16, $p=0.001$ ) with an absolute risk (AR) increase of $2.5 \%$ for any leukoaraiosis vs none. The RR was 2.4 ( $n=4,192 ; 95 \% \mathrm{Cl} 1.83-3.14, p=0.001)$ with an AR increase of $6.2 \%$ for moderate to severe vs no to mild leukoaraiosis. For poor functional outcome; the RR was $1.30(n=3,401 ; 95 \% \mathrm{Cl} 1.19-1.42, p=0.001)$ with an AR increase of $15.4 \%$ for any leukoaraiosis vs none. The RR was 1.31 ( $n=3,659 ; 95 \% \mathrm{Cl} 1.22-1.42, p=0.001)$ with an AR increase of $17.5 \%$ for moderate to severe vs no to mild leukoaraiosis. No statistical heterogeneity was noted for any of the analyses.

Conclusions: Leukoaraiosis presence and severity are consistently associated with an increased risk of sICH and poor functional outcome after IV or intra-arterial thrombolysis for acute ischemic stroke. Neurology ${ }^{\circledR}$ 2017;88:638-645

\section{GLOSSARY}

$\mathbf{C I}=$ confidence interval; $\mathbf{I C H}=$ intracerebral hemorrhage; $\mathbf{L A}=$ leukoaraiosis; $\mathbf{m R S}=$ modified Rankin Scale; $\mathbf{R C T}=$ randomized control trial; $\mathbf{R R}=$ relative risk; $\mathbf{s} \mathbf{C H}=$ symptomatic intracerebral hemorrhage; $\mathbf{t P A}=$ tissue plasminogen activator.

Thrombolytic therapy in acute ischemic stroke increases the risk of intracerebral hemorrhage (ICH). ${ }^{1}$ Symptomatic ICH (sICH) occurs in 2.4\%-10\% of patients within 24-36 hours after thrombolysis ${ }^{2-4}$ and is associated with an increased risk of subsequent death or disability. ${ }^{5}$ Imaging markers of small vessel disease, e.g., leukoaraiosis (LA) and cerebral microbleeds, are potential risk factors for thrombolysis-related $\mathrm{ICH}^{6,7}$ and poor clinical outcome. ${ }^{8,9}$

On plain CT, LA is denoted by bilateral (patchy or diffuse) areas of hypodensities in the periventricular white matter regions, which may extend to the centrum semiovale. ${ }^{10}$ On MRI, LA is seen on T2-weighted magnetic sequences as hyperintense signal, termed white matter

From the Stroke Research Centre (K.K., D.W., D.J.W.), Department of Brain Repair and Rehabilitation, UCL Institute of Neurology and The National Hospital for Neurology and Neurosurgery, Queen Square, London, UK; Division of Neurology, Department of Medicine, Faculty of Medicine (K.K., N.K., S.T.), and North-Eastern Stroke Research Group (K.K., N.K., S.T.), Khon Kaen University, Thailand; UCL School of Life \& Medical Sciences (F.J.), London, UK; Stroke Unit (V.P.), Department of Neurology, Careggi University Hospital, Florence, Italy; Hotchkiss Brain Institute (M.D.H.), Cumming School of Medicine, University of Calgary, Canada; Radcliffe Department of Medicine (A.M.B.), University of Oxford, John Radcliffe Hospital, UK; Department of Neurology (S.J., H.P.M.), Inselspital, University of Bern, Switzerland; and Departments of Neurology and Psychiatry (N.H.), University of Massachusetts Medical School, Worcester.

Go to Neurology.org for full disclosures. Funding information and disclosures deemed relevant by the authors, if any, are provided at the end of the article. The Article Processing Charge was paid by the British Heart Foundation.

This is an open access article distributed under the terms of the Creative Commons Attribution License 4.0 (CC BY), which permits unrestricted use, distribution, and reproduction in any medium, provided the original work is properly cited. 
Table 1 Pooled relative risk for symptomatic intracerebral hemorrhage (sICH) and poor functional outcome

\begin{tabular}{|c|c|c|c|c|c|}
\hline LA distribution & $\begin{array}{l}\text { Pooled absolute event } \\
\text { rates, } n / N(\%)\end{array}$ & $\begin{array}{l}\text { Pooled absolute } \\
\text { risk increase, \% }\end{array}$ & $\begin{array}{l}\text { Pooled } \\
\text { RR }\end{array}$ & $\begin{array}{l}\text { Lower } \\
95 \% \mathrm{Cl}\end{array}$ & $\begin{array}{l}\text { Upper } \\
95 \% \mathrm{Cl}\end{array}$ \\
\hline \multicolumn{6}{|l|}{ sICH } \\
\hline No LA & $115 / 2,779(4.1)$ & 2.5 & 1.65 & 1.26 & 2.16 \\
\hline LA & $184 / 2,772(6.6)$ & & & & \\
\hline \multicolumn{6}{|l|}{ sICH } \\
\hline No to mild LA & $140 / 3,470(4.0)$ & 6.2 & 2.40 & 1.83 & 3.14 \\
\hline $\begin{array}{l}\text { Moderate to } \\
\text { severe LA }\end{array}$ & 74/722 (10.2) & & & & \\
\hline \multicolumn{6}{|l|}{$\begin{array}{l}\text { Poor functional } \\
\text { outcome }\end{array}$} \\
\hline No LA & $839 / 1,594$ (52.6) & 15.4 & 1.30 & 1.19 & 1.42 \\
\hline LA & $1,230 / 1,807$ (68.0) & & & & \\
\hline \multicolumn{6}{|l|}{$\begin{array}{l}\text { Poor functional } \\
\text { outcome }\end{array}$} \\
\hline No to mild LA & $1,803 / 3,079$ (58.5) & 17.5 & 1.31 & 1.22 & 1.42 \\
\hline $\begin{array}{l}\text { Moderate to } \\
\text { severe LA }\end{array}$ & $441 / 580$ (76.0) & & & & \\
\hline
\end{tabular}

Abbreviations: $\mathrm{Cl}=$ confidence interval; $\mathrm{LA}=$ leukoaraiosis; $\mathrm{RR}=$ relative risk. Pooled relative risk for sICH and poor functional outcome (modified Rankin Scale score $\geq 2$ at 3 months) for different LA burden.

hyperintensities of presumed vascular origin. ${ }^{10}$ LA is primarily attributed to cerebral small vessel disease, causing chronic ischemic damage through disturbance of the microcirculation; LA has variable severity but typically progresses gradually over time, with the accumulation of vascular risk factors and advancing age. ${ }^{7}$ Data regarding the association between $\mathrm{LA}$ and sICH have been conflicting, with some studies reporting an increased risk of sICH and poor clinical outcome following thrombolysis for acute ischemic stroke, ${ }^{7,9,11-14}$ and others not. ${ }^{15-18}$ We therefore performed a systematic review and pooled meta-analysis of published studies to assess the evidence whether the presence of LA on neuroimaging before treatment with thrombolysis (IV/intra-arterial) is associated with an increased risk of sICH and poor functional outcome.

METHODS Search strategy and selection criteria. We searched MEDLINE and EMBASE between January 1, 1995, and September 1, 2015, using the following search terms: leukoaraiosis or white matter or small vessel disease(s) (SVD) in association with thromboly* or tPA or tissue plasminogen activator or fibrinoly*. We identified further studies from reference lists from publications and identified from the above search terms. We did not limit the search to any language. Case reports were excluded.

Eligibility criteria. Prospective or retrospective studies, which assessed sICH risk or functional outcome and rated LA on pretreatment CT or MRI in patients with acute ischemic stroke treated with thrombolysis, were included.
Data extraction. Two authors (K.K. and D.W.) read the abstracts of selected potentially relevant studies, reviewed the full text of those that appeared relevant, and extracted data independently. Both authors identified and read each study and resolved any differences by discussion with a third author (D.J.W.). We extracted information on type of study, number and characteristics of participants (including mean age and sex), neuroimaging parameters, duration of follow-up, number of participants with LA, number of participants with the outcome event $(\mathrm{sICH}$ defined according to standard criteria), and functional outcome. Consensus on the final studies included was reached by discussion. Where data were not available on $\mathrm{LA}, \mathrm{sICH}$, and the functional outcome, we contacted the study authors to request aggregate-level data. A flow chart of study selection is provided in figure e-1 at Neurology.org. Where all appropriate data were not extractable from the published articles, we contacted each study group to provide all required data for our analysis.

Quality assurance. We followed the Strengthening the Reporting of Observational Studies in Epidemiology as quality indicators ${ }^{19}$ and we prepared the article with reference to Meta-analyses of Observational Studies guidelines. ${ }^{20}$

LA definition and statistical analysis. LA severity was defined using various scales: the Gorter scale ${ }^{21}$; the van Swieten scale $^{22}$; the Blennow rating scale ${ }^{23}$; the Wahlund rating scale ${ }^{24}$; the Fazekas scale ${ }^{25}$; the Fazekas and Schmidt $(2003)^{26}$ scale; the Fazekas and Schmidt (1992) scale ${ }^{27}$; and the Scheltens score scale. ${ }^{28}$ Although combining scales potentially introduces heterogeneity, the good correlation for presence/absence and different severity grades among the different visual rating scales allows meaningful comparison of the results. ${ }^{29}$ Based on the findings reported, we first compared outcomes between the presence of any LA vs no LA; second, we compared outcomes between no to mild LA vs moderate to severe LA. We pooled data for both of these comparisons in separate meta-analyses.

For the sICH outcome (no LA vs any LA), we were able to combine all of the different scales, as no LA was defined the same regardless of scale (10 articles). ${ }^{11-18,30,31}$ Eight studies provided sICH risk between patients with no to mild LA vs moderate to severe LA; $2^{6,32}$ of 8 studies used the Fazekas and Schmidt 2003 (scores $0-1$ defined as no to mild and $2-3$ as moderate to severe). A total of $6^{7,12-14,16,31}$ of 8 studies used van Swieten (scores 0-2 defined as no to mild and 3-4 defined as moderate to severe).

For functional outcome at 3 months, the same analyses as above were undertaken: no vs any LA ( 8 articles) $)^{9,13-16,18,31,33}$ and no to mild vs moderate to severe (van Swieten ${ }^{22}$ ) (6 articles). ${ }^{7,9,13,14,16,31}$

We used a random-effects model to calculate the pooled relative risk (RR) of sICH and functional outcome in patients with vs without LA; weights were calculated using the inverse variance method. We assessed heterogeneity using $\mathrm{I}^{2}$ and $\chi^{2}$ statistics indicating the percentage of variance in a meta-analysis attributable to study heterogeneity and through visual inspection of the forest plots. We explored publication bias with funnel plots. We calculated pooled absolute risk between each group comparing any LA vs no LA and moderate to severe LA vs no to mild LA. Meta-analyses were performed using Stata 11.2 (StataCorp LP, College Station, TX).

RESULTS We identified 667 articles in our initial search of MEDLINE and EMBASE; 19 studies met our inclusion criteria. Nine articles provided the required data and we e-mailed the authors of the 
Figure 1 Forest plot of symptomatic intracerebral hemorrhage (sICH): Any leukoaraiosis (LA) vs no LA

\section{Study reference no.}

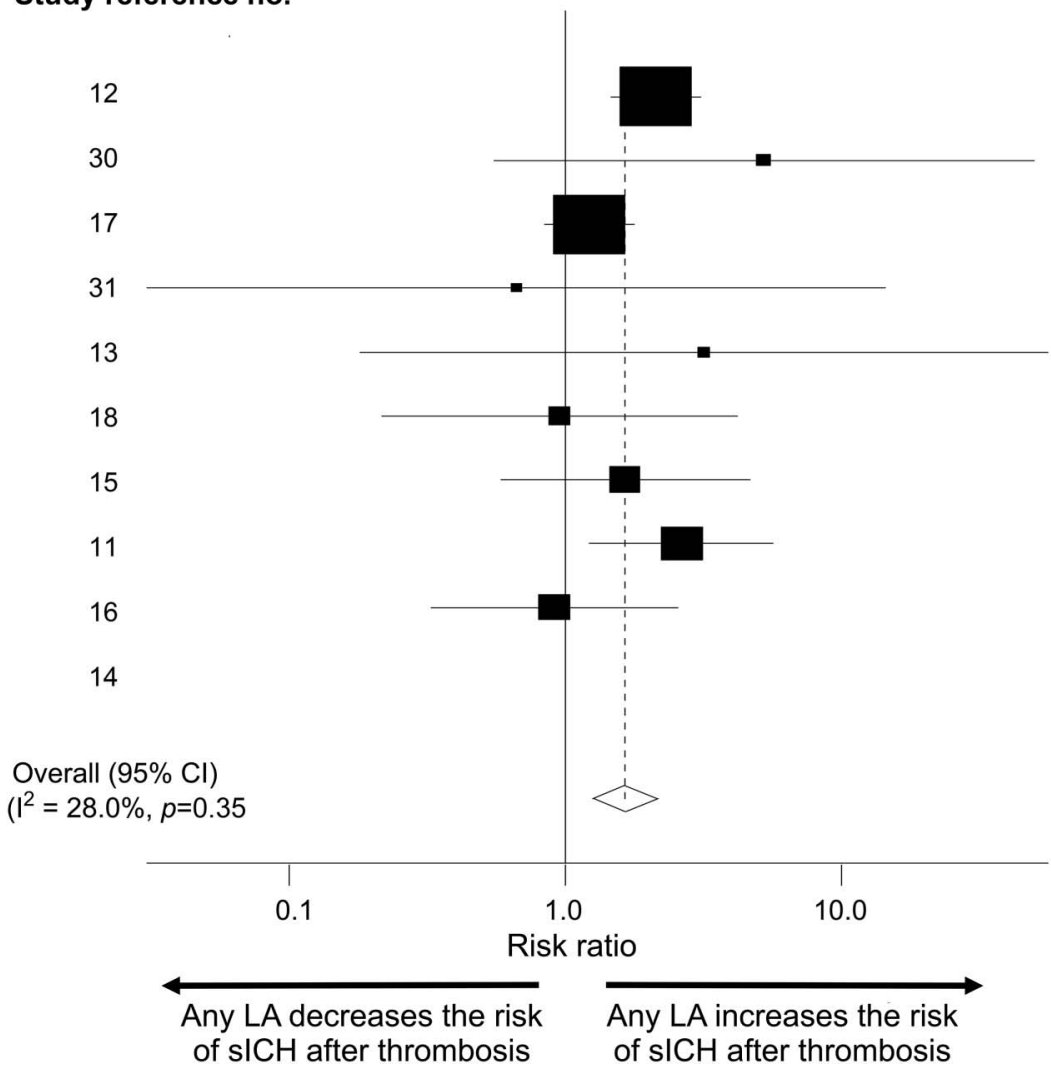

\section{$\operatorname{RR}(95 \% \mathrm{Cl})$}

$2.14(1.46,3.12) \quad 88 / 1324$

$5.26(0.55,49.94) \quad 3 / 113$

$1.23(0.84,1.79) \quad 57 / 765$

$0.67(0.03,14.45) \quad 1 / 26$

$3.18(0.18,55.97) \quad 3 / 21$

$0.96(0.22,4.24) \quad 10 / 245$

$1.65(0.58,4.68) \quad 6 / 56$

$2.64(1.22,5.71) \quad 11 / 97$

$0.92(0.33,2.57) \quad 5 / 99$

(Exclude)

$0 / 26$

$1.65(1.26,2.16) \quad 184 / 2772$
Events

No LA

$36 / 1157$

$1 / 198$

$45 / 742$

$0 / 5$

$0 / 9$

$2 / 47$

$7 / 108$

$13 / 303$

$11 / 200$

$0 / 10$

$115 / 2779$

\section{Weight
$\%$}

34.7

1.4

34.9

0.8

0.9

3.2

6.4

11.1

6.5

0.0

100.0

Forest plot of sICH-associated LA in post-thrombolysis patients: any $\mathrm{LA}$ vs no $\mathrm{LA}$. $\mathrm{Cl}=$ confidence interval; $\mathrm{RR}=$ relative risk.

remaining 10 articles to obtain the required data. Four articles (831 patients in total) were unable to provide functional outcome data. We included data from 15 articles including a total of 6,967 patients. The number of patients with LA was 2,934, giving an overall pooled prevalence of $42.1 \%$. A flow chart of study selection is shown in figure e-1. A summary of the characteristics of included studies is provided in tables e-1-e-5. Not all LA measures or outcomes were available from all studies; therefore different numbers of participants contributed to each analysis as described in detail below.

sICH risk. For this analysis, we included data from 10 articles $^{11-18,30,31}$ including 5,551 patients comparing sICH risk post thrombolysis between patients with no LA vs any LA. The total sICH rate was 299/5,551 (5.4\%). The sICH event rate in those with any LA was $6.6 \%$ vs $4.1 \%$ for those without LA; thus, any LA confers an absolute risk increase of $2.5 \%$ for sICH. The pooled RR of sICH risk was 1.65 (95\% confidence interval [CI] 1.26-2.16; $p=0.001$ ) in those with LA vs those without (figure 1). Heterogeneity $\left(\mathrm{I}^{2}\right)$ was $28.0 \%$ between the studies. In metaregression, 3 factors accounted for the heterogeneity as assessed by $\mathrm{I}^{2}$ : initial stroke severity (NIH Stroke Scale score), type of imaging (CT or MRI), and use of endovascular treatment. However, none of these variables was statistically associated with the outcome of interest $(\mathrm{sICH})$. There was no evidence of publication bias in the funnel plot (figure e-2).

Eight studies $6,7,9,13,14,16,31,32$ including 4,192 patients compared sICH risk post thrombolysis between patients with no to mild LA and moderate to severe LA. The total sICH rate was 214/4,192 (5.1\%). The sICH event rate in those with moderate to severe LA was $10.2 \%$ vs $4.0 \%$ for those no to mild LA; thus, moderate to severe LA confers an absolute risk increase of $6.2 \%$ for $\mathrm{sICH}$ (table 1). The pooled $\mathrm{RR}$ of sICH risk post thrombolysis was 2.40 (95\% CI $1.83-3.14 ; p=0.001$ ) for those with moderate to severe vs no to mild LA (figure 2). There was no significant heterogeneity between studies ( $\mathrm{I}^{2}$ was $0 \%)$. There was no evidence of publication bias in the funnel plot (figure e-2).

Functional outcome. For this analysis, data were available from 11 studies including a total of 5,823 patients. A summary of the characteristics of included studies is provided in tables e-1-e-5. Of the 11 available studies, $9^{7,9,13-16,18,31,33}$ provided data on poor functional outcome as modified Rankin Scale (mRS) score $\geq 2$ at 3 months. Two articles provided different outcomes (the ISTc group ${ }^{17}$ reported the 


\section{Study reference no.}

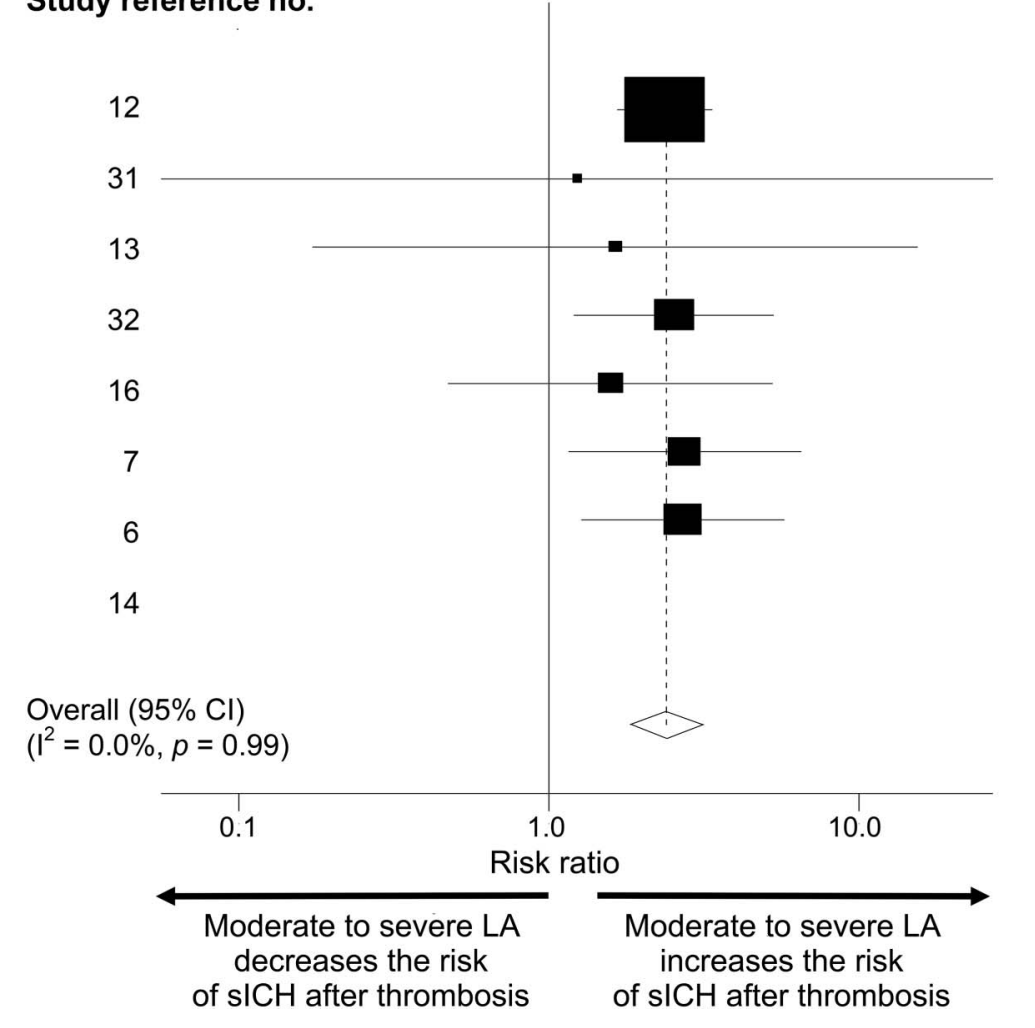

$\operatorname{RR}(95 \% \mathrm{Cl})$

$\begin{array}{lllr}2.38(1.67,3.39) & 44 / 466 & 80 / 2015 & 57.5 \\ 1.24(0.06,27.21) & 0 / 6 & 1 / 25 & 0.8 \\ 1.64(0.17,15.53) & 1 / 7 & 2 / 23 & 1.4 \\ 2.54(1.21,5.32) & 8 / 13 & 8 / 33 & 13.1 \\ 1.59(0.47,5.31) & 3 / 38 & 13 / 261 & 4.9 \\ 2.75(1.16,6.54) & 6 / 71 & 23 / 749 & 9.6 \\ 2.71(1.27,5.77) & 12 / 114 & 13 / 335 & 12.6 \\ \text { (Exclude) } & 0 / 7 & 0 / 29 & 0.0\end{array}$

$2.40(1.83,3.14) \quad 74 / 722 \quad 140 / 3470 \quad 100.0$

Forest plot of sICH-associated LA in post-thrombolysis patients: moderate to severe $\mathrm{LA}$ vs no to mild $\mathrm{LA}$. $\mathrm{Cl}=$ confidence interval; $\mathrm{RR}=$ relative risk.

Oxford Handicap scale $\geq 3$ at 6 months and Shi et al. ${ }^{32}$ reported $\mathrm{mRS} \geq 3$ at discharge) so could not be included in the meta-analysis.

Eight articles, including 3,401 patients, compared 3-month outcome between patients with no LA vs any LA. The total poor functional outcome rate was $2,069 / 3,401$ (60.8\%). The poor functional outcome event rate in those with any LA was $68.0 \%$ vs $52.6 \%$ for those without LA; thus, any LA confers an absolute risk increase of $15.4 \%$ for poor functional outcome (table 1). The pooled RR of poor functional outcome was 1.30 (95\% CI 1.19-1.42; $p=0.001)$ for those with any LA vs those without (figure 3). Heterogeneity $\left(\mathrm{I}^{2}\right)$ was $13.7 \%$ between the studies. In meta-regression, 3 factors accounted for heterogeneity as assessed by $\mathrm{I}^{2}$ : hypertension, use of endovascular treatment, and initial stroke severity (NIH Stroke Scale score). However, none of these variables was statistically associated with clinical outcome at 3 months. There was some evidence of publication bias in the funnel plot (figure e-2).

Six articles, including 3,659 patients, compared outcome at 3 months between no to mild LA and moderate to severe LA. The total poor functional outcome rate was 2,244/3,659 (61.3\%). The poor functional outcome event rate in those with moderate to severe LA was $76.0 \%$ vs $58.5 \%$ for those no to mild LA; thus, moderate to severe LA confers an absolute risk increase of $17.5 \%$ for poor functional outcome (table 1). The pooled RR of poor functional outcome was 1.31 (95\% CI 1.22-1.42; $p=0.001$ ) for those with moderate to severe LA vs no to mild LA (figure 4). Heterogeneity $\left(\mathrm{I}^{2}\right)$ was $13.2 \%$ between the studies. In meta-regression, 2 factors accounted for heterogeneity as assessed by $\mathrm{I}^{2}$ : hypertension and sex. However, neither of these variables was statistically associated with clinical outcome at 3 months. There was no evidence of publication bias in the funnel plot (figure e-2).

DISCUSSION Our systematic review and metaanalysis shows that the presence of LA on pretreatment neuroimaging is associated with an increased risk of sICH and poor functional outcome following thrombolytic treatment. Pooled analyses show that both presence and greater severity of LA are associated with a greater risk of sICH.

Our findings have biological plausibility. LA indicates presumed ischemic white matter injury in the territory of the penetrating small vessels in the distal deep arterial or arteriolar territories, associated with chronic endothelial dysfunction, and disruption of the blood-brain barrier. $^{34}$ The increased risk of sICH after thrombolysis may be explained by damage to the cerebral microcirculation 
Study reference no.

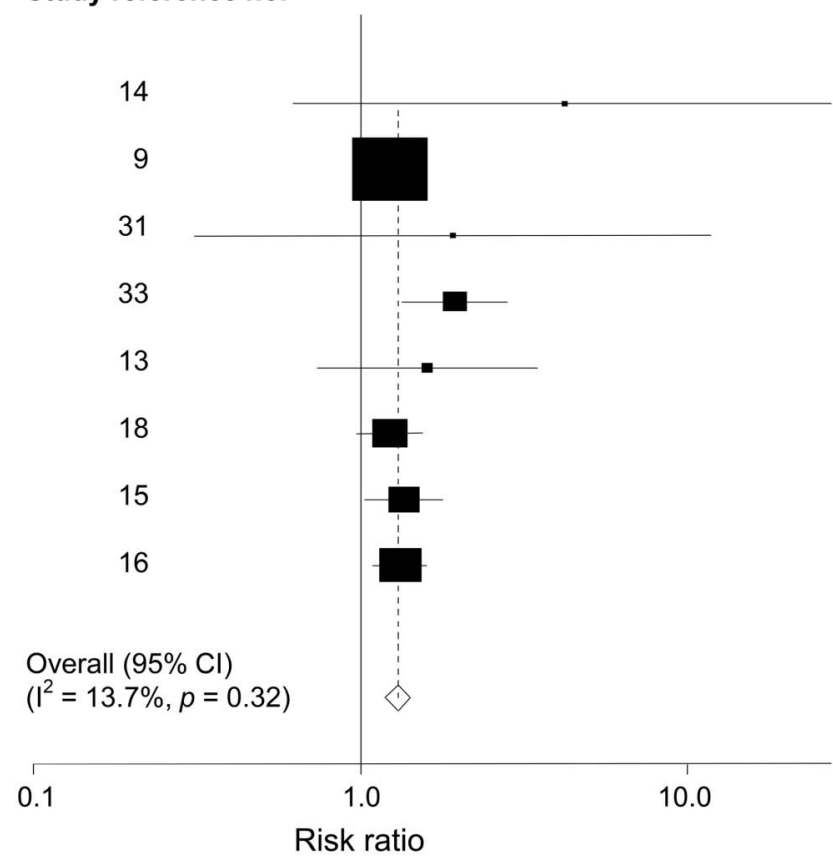

$\operatorname{RR}(95 \% \mathrm{Cl})$

$4.23(0.62,28.65)$

$1.24(1.16,1.32)$

$1.92(0.31,11.86)$

$1.95(1.34,2.83)$

$1.61(0.74,3.50)$

$1.23(0.97,1.56)$

$1.36(1.03,1.80)$

$1.33(1.09,1.61)$

$1.30(1.19,1.42)$

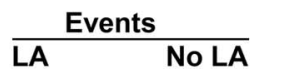

Weight

$11 / 26$

$1 / 10$

$894 / 1320$

$618 / 1131$

0.2

55.9

$10 / 26$

$1 / 5$

0.2

$13 / 17$

$33 / 84$

5.2

$15 / 21 \quad 4 / 9$

1.3

$184 / 242$

$29 / 47$

11.8

$36 / 56$

$51 / 108$

8.8

$67 / 99$

$102 / 200$

16.6

Any LA decreases the risk
of poor functional outcome $\begin{aligned} & \text { Any LA increases the risk } \\ & \text { of poor functional outcome }\end{aligned}$

Forest plot of modified Rankin Scale score $\geq 2$ at 3 months associated with LA in post-thrombolysis patients: any $L A$ vs no $L A$. $C I=$ confidence interval; $R R=$ relative risk.

causing increased small vessel fragility and susceptibility to vessel rupture and bleeding complications. ${ }^{11}$ In addition, LA is associated with platelet hyperactivation and hypercoagulability, ${ }^{35}$ which might reduce tissue perfusion after thrombolysis, leading to increased hemorrhagic transformation of the infarct.

Our pooled analyses show that both presence and greater severity of LA are associated with a poor functional outcome. LA might plausibly be relevant for stroke functional recovery: it is associated with cortical neuronal death, white matter disconnection that might result in decreased cerebral plasticity, and impaired learning during neurorehabilitation. ${ }^{36}$ Intact network connectivity of the brain is a critical factor for recovery from ischemic damage after acute stroke, ${ }^{15}$ which might be impaired by LA causing demyelination, loss of axons and oligodendrocytes, and astrocytic gliosis. ${ }^{37}$ Thus, due to these multiple mechanisms, LA could be related to increased risk of haemorrhage, delayed recovery, and impaired plasticity with poorer poststroke functional outcome. ${ }^{37}$ LA is also a risk factor for developing poststroke cognitive impairment, depression, difficulties in walking, and urinary incontinence that may eventually adversely affect patients' compliance with treatment and recovery programs. ${ }^{38}$

Our study has several strengths. We included a large number of patients. We undertook meta-regression to assess for heterogeneity and confounding. Furthermore, undertaking separate meta-analyses on no vs any LA and no to mild vs moderate to severe LA allows us to demonstrated a dose-response effect with a higher risk of sICH in those with more severe LA, which supports a biologically plausible causal association. Finally, our results are consistent with those from studies excluded from the meta-analysis as they measured functional outcome with different scales or time points.

There are some limitations of our analyses. First, the neuroimaging varied between studies, and included both CT and MRI, which is likely to affect the prevalence of LA. Nevertheless, our study shows that medium to high scores on ordinal scales indicating moderate to severe LA (easily detected on CT) carry a high risk of sICH risk compared to those with no to mild LA. This suggests that CT is sufficient to detect clinically relevant LA associated with increased sICH risk and poor functional outcome. Second, there was heterogeneity in thrombolysis protocols and the availability of some baseline characteristics; for example, hypertension, hyperglycemia, prior use of antiplatelet and anticoagulant medications, or recurrent stroke. Third, definitions in sICH varied, although we partially accounted for this heterogeneity by meta-regression. Fourth, there is likely to be 


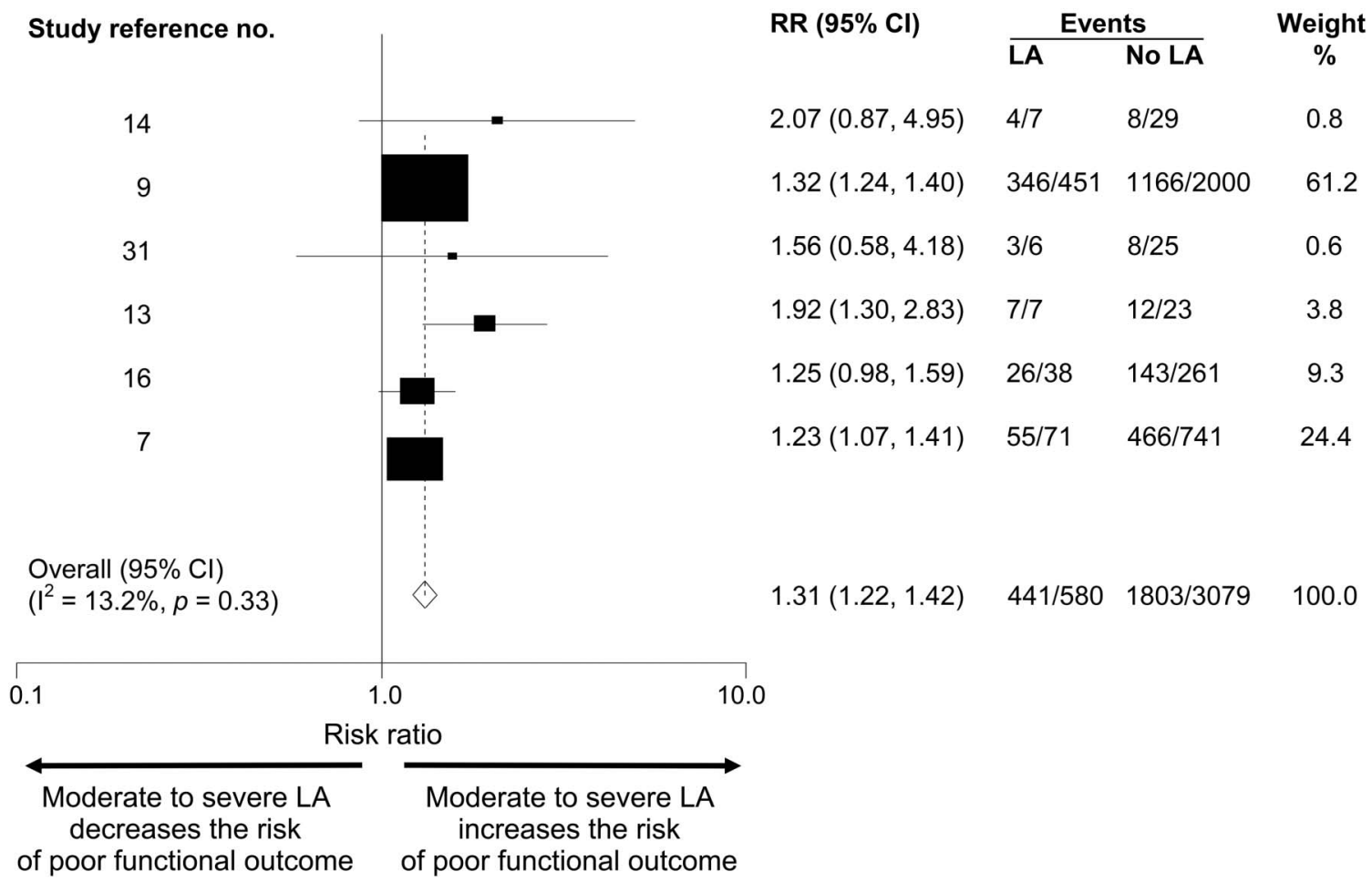

Forest plot of modified Rankin Scale score $\geq 2$ at 3 months associated with LA in post-thrombolysis patients: moderate to severe LA vs no to mild LA. CI = confidence interval; $\mathrm{RR}=$ relative risk.

selection bias in studies using MRI since unwell patients are more likely to be excluded, although the use of CT or MRI did not appear to be associated with any significant difference in the occurrence of sICH or poor functional outcome. Finally, we have not investigated the effect of ethnicity, which might be relevant for LA prevalence and sICH risk.

The poorer functional outcome in those with LA is likely to be due in part to the increased risk of sICH, particularly in those with moderate to severe LA, in whom the absolute risk was $6.2 \%$ higher than in those with no to mild LA. This association begs the question of whether thrombolysis should be withheld in patients with moderate to severe LA. All patients in our analysis were treated with thrombolysis, so we do not know the outcome in patients with or without LA where thrombolysis was withheld based on clinical judgement (which might have included an assessment of severe LA), so we cannot assess for interaction between LA and thrombolysis. In other words, the current study cannot determine whether those with moderate to severe LA would still derive benefit from thrombolysis treatment. Accordingly, our findings do not justify withholding thrombolytic therapy in patients with LA. Nevertheless, subanalysis of a randomized controlled trial shows that the beneficial effect of thrombolysis on favorable functional outcome (mRS 0-1) was only experienced in those without LA. ${ }^{16}$ Thus, our results might justify the need for future randomized control trials (RCTs) of thrombolysis to include stratification of patient outcomes by pretreatment LA. Until such time, other treatment options for those with moderate to severe LA with concern about high sICH risk include endovascular treatment (where a small unadjusted case series saw no difference in $\mathrm{sICH}$ rates according to LA grade) $)^{39}$ or lower dose tissue plasminogen activator (tPA), ${ }^{40}$ although there is currently no clear evidence supporting the latter strategy; subgroup analyses of the interaction of $\mathrm{PA}$ dose and pretreatment LA in a recent $\mathrm{RCT}^{40}$ will be of considerable interest.

Our analysis suggests an approximate doubling of the risk of sICH after thrombolysis for acute ischemic stroke if LA is present on pretreatment neuroimaging; the risk is highest for moderate to severe LA, which is easily detected on plain CT images. Importantly, LA is also associated with increased risk of poor functional outcome after thrombolysis therapy. However, in the absence of randomized trial data, our results do not justify withholding thrombolytic therapy from otherwise eligible candidates solely on the basis of LA presence on neuroimaging. Nevertheless, these data may be useful for clinicians in assessing likely sICH risk and functional outcome in individual patients, and for counseling patients and families about the expected outcome of thrombolytic therapy. 


\section{AUTHOR CONTRIBUTIONS}

K.K. was involved in study concept, data acquisition, and statistical analysis, and drafted the manuscript. D.W. was involved in data acquisition and statistical analysis and revised the manuscript. N.K. was involved in study concept and revised the manuscript. S.T. was involved in study concept and revised the manuscript. F.J. was involved in medical statistics. V.P. contributed data, was involved in data acquisition, and revised the manuscript. M.D.H contributed data, was involved in data acquisition, and revised the manuscript. A.M.B. contributed data, was involved in data acquisition, and revised the manuscript. S.J. contributed data, was involved in data acquisition, and revised the manuscript. H.P.M. contributed data, was involved in data acquisition, and revised the manuscript. N.H. contributed data, was involved in data acquisition, and revised the manuscript. D.J.W. was involved in study concept, data acquisition, and statistical analysis, and revised the manuscript.

\section{STUDY FUNDING}

Dr. Kongbunkiat receives research support from Faculty of Medicine, Khon Kaen University, Khon Kaen, Thailand. Dr. Werring receives research support from the Stroke Association, British Heart Foundation, and the Rosetrees Trust. Dr. Wilson receives research support from the Stroke Association and British Heart Foundation. Dr. Henninger is supported by K08NS091499 from the National Institute of Neurologic Disorders and Stroke of the NIH. The content is solely the responsibility of the authors and does not necessarily represent the official views of the NIH. This work was undertaken at UCLH/UCL, which received a proportion of funding from the Department of Health's NIHR Biomedical Research Centres funding scheme.

\section{DISCLOSURE}

The authors report no disclosures relevant to the manuscript. Go to Neurology.org for full disclosures.

Received May 13, 2016. Accepted in final form September 27, 2016.

\section{REFERENCES}

1. Lindley RI, Wardlaw JM, Sandercock PA, et al. Frequency and risk factors for spontaneous hemorrhagic transformation of cerebral infarction. J Stroke Cerebrovasc Dis 2004;13: 235-246.

2. The National Institute of Neurological Disorders and Stroke rt-PA Stroke Study Group. Tissue plasminogen activator for acute ischemic stroke. N Engl J Med 1995; 333:1581-1587.

3. Derex L, Nighoghossian N. Intracerebral haemorrhage after thrombolysis for acute ischaemic stroke: an update. J Neurol Neurosurg Psychiatry 2008;79:1093-1099.

4. Karaszewski B, Houlden H, Smith EE, et al. What causes intracerebral bleeding after thrombolysis for acute ischaemic stroke? Recent insights into mechanisms and potential biomarkers. J Neurol Neurosurg Psychiatry 2015;86:1127-1136.

5. Strbian D, Sairanen T, Meretoja A, et al. Patient outcomes from symptomatic intracerebral hemorrhage after stroke thrombolysis. Neurology 2011;77:341-348.

6. Neumann-Haefelin T, Hoelig S, Berkefeld J, et al. Leukoaraiosis is a risk factor for symptomatic intracerebral hemorrhage after thrombolysis for acute stroke. Stroke 2006;37:2463-2466

7. Palumbo V, Boulanger JM, Hill MD, Inzitari D, Buchan AM, Investigators C. Leukoaraiosis and intracerebral hemorrhage after thrombolysis in acute stroke. Neurology 2007;68: 1020-1024.

8. Arsava EM, Rahman R, Rosand J, et al. Severity of leukoaraiosis correlates with clinical outcome after ischemic stroke. Neurology 2009;72:1403-1410.

9. Curtze S, Melkas S, Sibolt G, et al. Cerebral computed tomography-graded white matter lesions are associated with worse outcome after thrombolysis in patients with stroke. Stroke 2015;46:1554-1560.

10. Hachinski VC, Potter P, Merskey H. Leukoaraiosis. Arch Neurol 1987;44:21-23.

11. Aries MJ, Uyttenboogaart M, Vroomen PC, De Keyser J, Luijckx GJ. tPA treatment for acute ischaemic stroke in patients with leukoaraiosis. Eur J Neurol 2010;17:866-870.

12. Curtze S, Haapaniemi E, Melkas $S$, et al. White matter lesions double the risk of post-thrombolytic intracerebral hemorrhage. Stroke 2015;46:2149-2155.

13. Henninger N, Lin E, Baker SP, Wakhloo AK, Takhtani D, Moonis M. Leukoaraiosis predicts poor 90-day outcome after acute large cerebral artery occlusion. Cerebrovasc Dis 2012;33:525-531.

14. Onteddu SR, Goddeau RP Jr, Minaeian A, Henninger N. Clinical impact of leukoaraiosis burden and chronological age on neurological deficit recovery and 90-day outcome after minor ischemic stroke. J Neurol Sci 2015;359:418-423.

15. Choi JH, Bae HJ, Cha JK. Leukoaraiosis on magnetic resonance imaging is related to long-term poor functional outcome after thrombolysis in acute ischemic stroke. J Korean Neurosurg Soc 2011;50:75-80.

16. Demchuk AM, Khan F, Hill MD, et al. Importance of leukoaraiosis on CT for tissue plasminogen activator decision making: evaluation of the NINDS rt-PA Stroke Study. Cerebrovasc Dis 2008;26:120-125.

17. The ISTc group. Association between brain imaging signs, early and late outcomes, and response to intravenous alteplase after acute ischaemic stroke in the third International Stroke Trial (IST-3): secondary analysis of a randomised controlled trial. Lancet Neurol 2015;14:485-496.

18. Jung S, Mono ML, Findling O, et al. White matter lesions and intra-arterial thrombolysis. J Neurol 2012;259:1331-1336.

19. White RG, Hakim AJ, Salganik MJ, et al. Strengthening the Reporting of Observational Studies in Epidemiology for respondent-driven sampling studies: "STROBE-RDS" statement. J Clin Epidemiol 2015;68:1463-1471.

20. Stroup DF, Berlin JA, Morton SC, et al. Meta-analysis of observational studies in epidemiology: a proposal for reporting. Meta-analysis Of Observational Studies in Epidemiology (MOOSE) group. JAMA 2000;283:2008-2012.

21. Gorter JW. Major bleeding during anticoagulation after cerebral ischemia: patterns and risk factors: Stroke Prevention In Reversible Ischemia Trial (SPIRIT): European Atrial Fibrillation Trial (EAFT) study groups. Neurology 1999;53:1319-1327.

22. van Swieten JC, Hijdra A, Koudstaal PJ, van Gijn J. Grading white matter lesions on CT and MRI: a simple scale. J Neurol Neurosurg Psychiatry 1990;53:1080-1083.

23. Blennow K, Wallin A, Uhlemann C, Gottfries CG. White-matter lesions on CT in Alzheimer patients: relation to clinical symptomatology and vascular factors. Acta Neurol Scand 1991;83:187-193.

24. Wahlund LO, Barkhof F, Fazekas F, et al. A new rating scale for age-related white matter changes applicable to MRI and CT. Stroke 2001;32:1318-1322.

25. Fazekas F, Chawluk JB, Alavi A, Hurtig HI, Zimmerman RA. MR signal abnormalities at $1.5 \mathrm{~T}$ in Alzheimer's dementia and normal aging. AJR Am J Roentgenol 1987;149: 351-356.

26. Kapeller P, Barber R, Vermeulen RJ, et al. Visual rating of age-related white matter changes on magnetic resonance imaging: scale comparison, interrater agreement, and correlations with quantitative measurements. Stroke 2003;34:441-445. 
27. Schmidt R, Fazekas F, Kleinert G, et al. Magnetic resonance imaging signal hyperintensities in the deep and subcortical white matter: a comparative study between stroke patients and normal volunteers. Arch Neurol 1992;49: 825-827.

28. Scheltens P, Barkhof F, Leys D, et al. A semiquantative rating scale for the assessment of signal hyperintensities on magnetic resonance imaging. J Neurol Sci 1993;114 7-12.

29. Pantoni L, Simoni M, Pracucci G, Schmidt R, Barkhof F, Inzitari D. Visual rating scales for age-related white matter changes (leukoaraiosis): can the heterogeneity be reduced? Stroke 2002;33:2827-2833.

30. Willer L, Havsteen I, Ovesen C, Christensen AF, Christensen H. Computed tomography-verified leukoaraiosis is a risk factor for post-thrombolytic hemorrhage. J Stroke Cerebrovasc Dis 2015;24:1126-1130.

31. Henninger $\mathrm{N}$, Khan MA, Zhang J, Moonis M, Goddeau RP Jr. Leukoaraiosis predicts cortical infarct volume after distal middle cerebral artery occlusion. Stroke 2014;45:689-695.

32. Shi ZS, Loh Y, Liebeskind DS, et al. Leukoaraiosis predicts parenchymal hematoma after mechanical thrombectomy in acute ischemic stroke. Stroke 2012;43:1806-1811.

33. Huang YH, Zhuo ST, Chen YF, et al. Factors influencing clinical outcomes of acute ischemic stroke treated with intravenous recombinant tissue plasminogen activator. Chin Med J 2013;126:4685-4690.

34. del Zoppo GJ, von Kummer R, Hamann GF. Ischaemic damage of brain microvessels: inherent risks for thrombolytic treatment in stroke. J Neurol Neurosurg Psychiatry 1998;65:1-9

35. Iwamoto T, Kubo H, Takasaki M. Platelet activation in the cerebral circulation in different subtypes of ischemic stroke and Binswanger's disease. Stroke 1995;26:52-56.

36. O'Sullivan M. Imaging small vessel disease: lesion topography, networks, and cognitive deficits investigated with MRI. Stroke 2010;41:S154-S158.

37. Yamanouchi H, Sugiura S, Tomonaga M. Decrease in nerve fibres in cerebral white matter in progressive subcortical vascular encephalopathy of Binswanger type. An electron microscopic study. J Neurol 1989;236:382-387.

38. De Groot JC, De Leeuw FE, Oudkerk M, et al. Periventricular cerebral white matter lesions predict rate of cognitive decline. Ann Neurol 2002;52:335-341.

39. Zhang J, Puri AS, Khan MA, Goddeau RP Jr, Henninger N. Leukoaraiosis predicts a poor 90-day outcome after endovascular stroke therapy. Am J Neuroradiol 2014;35: 2070-2075.

40. Anderson CS, Robinson T, Lindley RI, et al. Low-dose versus standard-dose intravenous alteplase in acute ischemic stroke. N Engl J Med 2016;374:2313-2323.

\section{This Week's Neurology ${ }^{\circledR}$ Podcast}

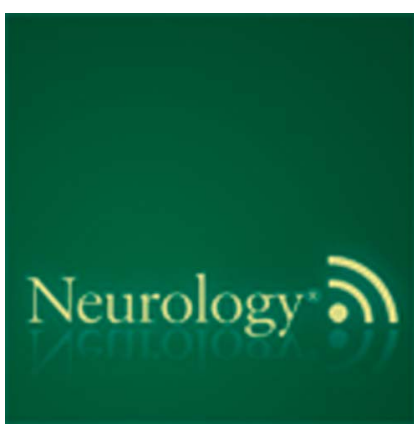

Prognosis of carotid dissecting aneurysms: Results from CADISS and a systematic review (see p. 646)

This podcast begins and closes with Dr. Robert Gross, Editor-inChief, briefly discussing highlighted articles from the February 14, 2017, issue of Neurology. In the first segment, Dr. Andy Southerland interviews Dr. Hugh Markus about his paper on the prognosis of carotid dissecting aneurysms. Dr. Robert Gross talks with Dr. Brian Callaghan and Dr. Kevin Kerber about Innovations in Care Delivery, one of two new Neurology minisites, for our "What's Trending" feature of the week. In the next part of the podcast, Dr. Ted Burns focuses his interview with Dr. John Noseworthy on a Neurology Today ${ }^{\circledR}$ story titled At the Helm: The Neurologist as National Health Care Leader: Mayo Clinic's John M. Noseworthy, $M D$.

Disclosures can be found at Neurology.org.

At Neurology.org, click on "RSS" in the Neurology Podcast box to listen to the most recent podcast and subscribe to the RSS feed.

CME Opportunity: Listen to this week's Neurology Podcast and earn 0.5 AMA PRA Category

1 CME Credits ${ }^{\mathrm{TM}}$ by answering the multiple-choice questions in the online Podcast quiz. 


\section{Neurology}

\section{Leukoaraiosis, intracerebral hemorrhage, and functional outcome after acute stroke}

thrombolysis

Kannikar Kongbunkiat, Duncan Wilson, Narongrit Kasemsap, et al. Neurology 2017;88;638-645 Published Online before print January 27, 2017

DOI 10.1212/WNL.0000000000003605

This information is current as of January 27, 2017

Neurology ${ }^{\circledR}$ is the official journal of the American Academy of Neurology. Published continuously since 1951, it is now a weekly with 48 issues per year. Copyright Copyright (C) 2017 The Author(s). Published by Wolters Kluwer Health, Inc. on behalf of the American Academy of Neurology. All rights reserved. Print ISSN: 0028-3878. Online ISSN: 1526-632X.

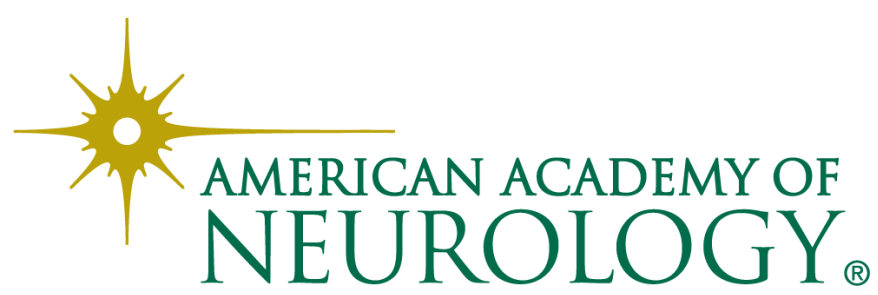




\section{Updated Information \& Services}

\section{Supplementary Material}

\section{References}

Citations

Subspecialty Collections

Permissions \& Licensing

\section{Reprints}

including high resolution figures, can be found at:

http://n.neurology.org/content/88/7/638.full

Supplementary material can be found at: http://n.neurology.org/content/suppl/2017/01/27/WNL.0000000000003 605.DC1

http://n.neurology.org/content/suppl/2017/02/13/WNL.0000000000003 605.DC2

This article cites 40 articles, 19 of which you can access for free at: http://n.neurology.org/content/88/7/638.full\#ref-list-1

This article has been cited by 5 HighWire-hosted articles: http://n.neurology.org/content/88/7/638.full\#\#otherarticles

This article, along with others on similar topics, appears in the following collection(s):

\section{All Cerebrovascular disease/Stroke}

http://n.neurology.org/cgi/collection/all_cerebrovascular_disease_strok e

Clinical trials Systematic review/meta analysis

http://n.neurology.org/cgi/collection/clinical_trials_systematic_review_ meta_analysis_

Infarction

http://n.neurology.org/cgi/collection/infarction

Intracerebral hemorrhage

http://n.neurology.org/cgi/collection/intracerebral_hemorrhage

Information about reproducing this article in parts (figures,tables) or in its entirety can be found online at:

http://www.neurology.org/about/about_the_journal\#permissions

Information about ordering reprints can be found online:

http://n.neurology.org/subscribers/advertise

Neurology ${ }^{\circledR}$ is the official journal of the American Academy of Neurology. Published continuously since 1951, it is now a weekly with 48 issues per year. Copyright Copyright ( 2017 The Author(s). Published by Wolters Kluwer Health, Inc. on behalf of the American Academy of Neurology. All rights reserved. Print ISSN: 0028-3878. Online ISSN: 1526-632X.

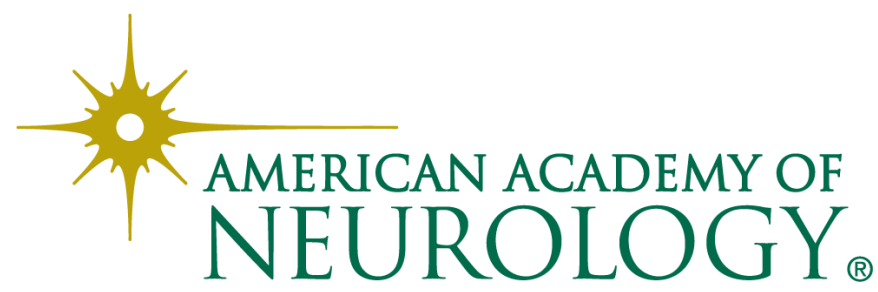

